\title{
Associations of Zinc-a-2-glycoprotein with Metabolic Syndrome and its Components Among Adult Arabs
}

\author{
Nasser Al-Daghri ( $\square$ aldaghri2011@gmail.com ) \\ King Saud University \\ Amal Alenad \\ King Saud University \\ Lamya Alkaltham \\ King Saud University \\ Shaun Sabico \\ King Saud University \\ Malak Khattak \\ King Saud University \\ Syed Hussain \\ King Saud University
}

\section{Research Article}

Keywords: Metabolic Syndrome, Zinc-alpha glycoprotein, Biomarker, Hypertriglyceridemia

Posted Date: September 2nd, 2021

DOl: https://doi.org/10.21203/rs.3.rs-845832/v1

License: (1) This work is licensed under a Creative Commons Attribution 4.0 International License. Read Full License 


\section{Abstract}

Background: Epidemiological studies suggest that the Zinc-a-2-glycoprotein (ZAG) plays significant physiological roles. In this study we investigate whether ZAG could be considered as a clinical biomarker in the diagnosis and prognosis of metabolic syndrome (MetS) in Saudi population. As such insights urgently required for management of MetS. Thus, we have determined serum levels of ZAG in patients with MetS and normal individuals. We have also assessed the association between ZAG and different components of MetS.

Methodology: Clinical information of 200 Saudi male and female subjects (age range 30-65) with MetS $(n=100)$ and healthy controls $(n=100)$ were extracted from the database of the Chair of Biomarkers of Chronic Disease (CBCD) in King Saud University (KSU), Riyadh, Saudi Arabia. MetS was screened according to NCEP ATP III criteria (National Cholesterol Education Program Adult Treatment Panel III). Fasting glucose and lipid profile levels were measured using Konelab. Serum TNF-a, IL-6, CRP and ZAG levels were measured using commercially available assays.

Results: There was age-dependent significant increase in ZAG level among MetS subjects than controls (43.8 \pm 19.5 vs $48.1 \pm 14.8 ; p=0.04)$. This study demonstrates, a significant inverse association between $Z A G$ and serum HDL-cholesterol $(R=-0.20, p<0.05)$. Whereas, triglycerides $(R=0.25, p<0.01)$, waist circumference $(W H R)(R=0.17, p<0.05)$ and $C R P(R=0.24, p<0.01)$ were all significantly and positively associated with ZAG.

Conclusion: High level of circulating ZAG is associated with MetS in age dependent manner. Serum ZAG might be a biomarker for MetS screening.

\section{Introduction}

Metabolic syndrome (MetS) is a complicated disorder. Developments of proinflammatory and prothrombotic state are a potential mechanism contributing to the pathophysiology of MetS, due to adipocytes cytokine production. There are also several hypothesized mechanisms that are underlying the etiology of MetS, which involves the insulin resistance (IR) with fatty acid flux, low-level chronic inflammation and oxidative stress ${ }^{1}$. Obesity-mediated MetS and IR are increasingly heavy affliction in Saudi society. In a study involved 17,293 Saudi patients, the results showed that the prevalence of MetS were high in Saudi Arabia (39.3\%). Moreover, females have a higher prevalence of MetS than males ${ }^{2}$. Low-level chronic inflammation combined with increased fat mass and damaging lipid profiles is associated with the pathophysiology of MetS and IR ${ }^{1}$. Increase in adipocyte has been shown to cause abundance of proinflammatory cytokines such as IL- 6 , resistin, TNF- $\alpha$ and CRP, and this could be due the presence of macrophages in adipose tissue which might be partially the source of the production of proinflammatory cytokines ${ }^{3}$. IR also was found to be associated with overproduction of proinflammatory cytokines and relative deficiency of adiponectin in muscle and liver ${ }^{3}$. 
Growing evidence suggest that altered production of adipose-derived protein factors such as Zinc- a -2glycoprotein (ZAG) plays an important role in the pathophysiology of obesity and its associated complications such as MetS ${ }^{4,5}$. ZAG gene expression in adipocytes is primarily controlled by androgens and progestins, and Glucocorticoids ${ }^{6}$. Epidemiological studies showed that, the levels of serum ZAG were positively correlated with the levels of serum triglycerides (TAG) and adipocyte fatty acid-binding protein, whereas the levels of ZAG were inversely associated with HDL-cholesterol ${ }^{7}$. Overexpression of ZAG in cultured hepatocytes significantly inhibited lipogenesis by decrease metabolic nuclear receptors sterol regulatory element-binding protein (SREBP-1c), liver $X$ receptor (LXR) and lipogenic enzymes in the liver, also lipolysis and fatty acid $\beta$-oxidation were stimulated. On the other hand, knocking down of ZAG resulted in inhibition of fatty acid $\beta$-oxidation, increased lipogenesis and lipid accumulation ${ }^{8}$. Findings of these studies suggest an important role of ZAG in lipolysis, and that the way ZAG is involved in lipid metabolism, is by enhancing the conversion of white adipose tissue into brown adipose tissue. The suggested mechanism of ZAG exerting its effect on white adipose tissue, is by increasing the expression of the peroxisome proliferator-activated receptor $\mathrm{C}$ (PPARc) and early B cell factor 2 , that are considered in promoting cascade expression of genes involved in browning of the adipose tissue ${ }^{9}$.

We hypothesized that MetS components have different effects on the circulating levels of ZAG. Therefore, the aim of this study was to investigate the relationship between circulating ZAG level and MetS as well as its components, to provide an insight for predicting the occurrence of MetS in Saudi patients. Additional aim of the study was to assess circulating levels of ZAG and Proinflammatory Cytokines, CRP, IL- 6 and TNF-a in patients with or without MetS. We also compared the characteristics of each MetS component in the study population.

\section{Materials And Method}

\section{Subjects}

A total of 200 adult Saudi subjects (94 men; 106 women), aged 23-65 years were randomly selected from the database of Biomarker Screening in Riyadh Project (RIYADH COHORT) collected by Center for Biomarkers in Chronic Diseases (CBCD) in Riyadh, KSA. All participants provided written and informed consent prior to inclusion. Ethical approval was granted by the Ethics Committee of the College of Science Research Center, King Saud University, Riyadh, Kingdom of Saudi Arabia (KSA). Participants completed a questionnaire their general health status, demographic information, and past medical history. Anthropometric and biochemical data from the database was utilized to assess the status of full MetS and its five components as present/absent (dichotomous data) according to the criteria set in the National Cholesterol Education Programme Adult Treatment Panel III (NCEP-ATP III) where MetS was present when at least three out of the five following components are present: Waist circumference of $>88$ $\mathrm{cm}$; fasting glucose $>5.6 \mathrm{mmol} / \mathrm{L}$; HDL-cholesterol < $1.30 \mathrm{mmol} / \mathrm{L}$; triglycerides $>1.7 \mathrm{mmol} / \mathrm{L}$; systolic blood pressure $>130 \mathrm{mmHg}$ and/or diastolic blood pressure $>85 \mathrm{mmHg}{ }^{10}$. 
The sample size was calculated based on an earlier study by Yeung et al. ${ }^{7}$ where serum Zinc-alpha2Glycoprotein in MetS patients was reported with an effect size of $>0.5$. Thus, a total sample size of 176 subjects (88 per group) was required to detect the effect size of 0.5 with $95 \%$ power using $5 \%$ significance level. Based on this, 100 MetS and 100 non-MetS subjects were selected from the database by random selection based on the RAND function in the Microsoft excel. Prior to the final selection, the subjects with reported chronic conditions like liver, kidney, heart failures and pregnant women were removed from the selection and the process was repeated to get the final count of 100 in each group.

\section{Inclusion and exclusion criteria}

Subjects on anti-hyperglycemic treatment; pregnant or lactating women; with known renal, hepatic, pulmonary, cardiac, etc., complications were excluded from this study.

\section{Anthropometry and Blood Collection}

Anthropometry included height $(\mathrm{cm})$, weight $(\mathrm{kg})$, waist and hip circumference $(\mathrm{cm})$, and mean systolic and diastolic blood pressure ( $\mathrm{mmHg}$, average of two reading). Body mass index (BMI) was calculated as weight in kilograms divided by height in square meters. Waist-hip ratio (WHR) was calculated as the quotient between waist and hip circumferences. They were asked to fast 10 hours or overnight before blood withdrawal. Fasting blood samples $(>10 \mathrm{~h}$ ) were collected and transferred immediately to a nonheparinized tube for centrifugation. The collected serum was transferred to pre-labeled new tubes, kept on ice, and delivered to the CBCD in King Saud University, Riyadh, KSA, for immediate storage at $-20^{\circ} \mathrm{C}$.

\section{Blood Chemistry}

Fasting blood glucose and lipid profile (triglycerides, total and HDL-cholesterol) were assessed using routine chemical methods (Konelab analyzer, Espoo Finland). Hypertriglyceridemia was defined as circulating triglycerides $\geq 1.7 \mathrm{mmol} / \mathrm{I}$ was considered abnormal level ${ }^{11}$. Low HDL-cholesterol was defined as $<1.03 \mathrm{mmol} / \mathrm{l}$ and total cholesterol HDL ratio $>3.5$. Low-HDL level for women was set at $<1.3 \mathrm{mmol} / \mathrm{l}$ 12,13 .

\section{Inflammatory markers and ZAG}

Serum TNF- $\alpha$ and IL-6 level were determined using MILLIPLEX MAP human adipokine magnetic bead panel 2 kit obtained from Millipore Corporation. Serum human CRP level were determined using ELISA kits obtained from R\&D System, USA. Serum ZAG level were determined using ELISA kits using BioVendor-Laboratory Medicine.

\section{Data analysis}


Data were analyzed using SPSS (version 22 Chicago, IL, USA). Continuous data were presented as mean \pm standard deviation (SD) for normal variables and non-Gaussian variables were presented in median (1st and 3 rd ) percentiles. Categorical data were presented as frequencies and percentages (\%). All continuous variables were checked for normality using Kolmogorov-Smirnov test. Non-Gaussian variables were logtransformed prior to parametric analysis. Independent T-test and Mann Whitney U were used to compare mean differences in Gaussian and Non-Gaussian variables. Correlations between variables were done using Pearson's and spearman correlation analysis. Stepwise regression analysis was performed for dependent predicators of ZAG ( $\mathrm{ug} / \mathrm{ml}$ ) and area under the curve (AUC) was calculated using receiver operating characteristic (ROC) curve to determine viability of ZAG as a biomarker for MetS and its components. An AUC of 0.9 to 1 is considered excellent, 0.8 to 0.9 is considered good, 0.7 to 0.8 is considered fair, 0.6 to 0.7 is considered poor, and 0.5 to 0.6 is considered very poor. A p-value $<0.05$ was considered statistically significant.

\section{Results}

\section{General characteristics of the study subjects}

A total of 200 subjects (94 males and 106 females), age range $30-65$; mean BMI $29.8 \pm 5.5 \mathrm{~kg} / \mathrm{m} 2$ ) participated in this study. $50 \%$ of all subjects were considered as MetS subject, with significant increase in blood pressure, fasting glucose and triglycerides. Also, there was a decrease in HDL-Cholesterol among the MetS subjects. TNF- $a$ and CRP were significantly elevated in MetS subjects than normal subjects (Table 1). 
Table 1

Clinical Characteristics of all Subjects.

\begin{tabular}{|c|c|c|c|c|c|}
\hline Parameters & All & Normal & MetS & \multirow{2}{*}{$\begin{array}{l}P \text { - } \\
\text { value }\end{array}$} & \multirow{3}{*}{$\begin{array}{l}\text { Age adjusted P- } \\
\text { value }\end{array}$} \\
\hline $\mathbf{N}$ & 200 & $100(50 / 50)$ & $100(44 / 56)$ & & \\
\hline Age (years) & $38.7 \pm 8.3$ & $35.4 \pm 7.9$ & $41.9 \pm 7.2$ & $<.001$ & \\
\hline Height (cm) & $164.0 \pm 9.9$ & $164.0 \pm 10.1$ & $164.1 \pm 9.9$ & 0.99 & 0.54 \\
\hline Weight (kg) & $80.1 \pm 16.6$ & $74.7 \pm 17.1$ & $85.5 \pm 14.3$ & $<.001$ & $<0.001$ \\
\hline $\mathrm{BMI}\left(\mathrm{kg} / \mathrm{m}^{2}\right)$ & $29.8 \pm 5.5$ & $27.7 \pm 5.2$ & $31.9 \pm 5.1$ & $\begin{array}{l}< \\
0.001\end{array}$ & $<0.001$ \\
\hline Waist (cm) & $96.4 \pm 17.6$ & $87.6 \pm 14.9$ & $105.6 \pm 15.5$ & $<.001$ & $<0.001$ \\
\hline Hips (cm) & $106.6 \pm 13.7$ & $104.8 \pm 12.9$ & $108.5 \pm 14.2$ & 0.053 & 0.10 \\
\hline WHR & $0.91 \pm 0.2$ & $0.84 \pm 0.11$ & $0.98 \pm 0.17$ & $<.001$ & $<0.001$ \\
\hline SBP (mm Hg) & $123.5 \pm 16.3$ & $117.4 \pm 12.2$ & $129.7 \pm 17.5$ & $<0.001$ & $<0.001$ \\
\hline $\mathrm{DBP}(\mathrm{mm} \mathrm{Hg})$ & $74.9 \pm 11.1$ & $70.9 \pm 9.2$ & $78.9 \pm 11.4$ & $<.001$ & $<0.001$ \\
\hline \multicolumn{6}{|l|}{ Lipid Profiles } \\
\hline $\begin{array}{l}\text { Total Cholesterol } \\
(\mathrm{mmo} / \mathrm{l})\end{array}$ & $5.3 \pm 1.3$ & $5.2 \pm 1.0$ & $5.5 \pm 1.6$ & 0.19 & 0.37 \\
\hline $\begin{array}{l}\text { HDL-Cholesterol } \\
(\mathrm{mmol} / \mathrm{l})\end{array}$ & $1.13 \pm 0.3$ & $1.23 \pm 0.3$ & $1.03 \pm 0.3$ & $<.001$ & $<0.001$ \\
\hline LDL-Cholesterol & $3.3 \pm 1.2$ & $3.4 \pm 0.9$ & $3.3 \pm 1.4$ & 0.78 & 0.53 \\
\hline $\begin{array}{l}\text { Triglycerides } \\
(\mathrm{mmol} / \mathrm{l}) \#\end{array}$ & $1.85 \pm 0.9$ & $1.34 \pm 0.7$ & $2.37 \pm 0.8$ & $<.001$ & $<0.001$ \\
\hline \multicolumn{6}{|l|}{ Glycemic profile } \\
\hline Glucose (mmol/l) & $6.2 \pm 2.6$ & $5.2 \pm 0.7$ & $7.1 \pm 3.3$ & $<.001$ & $<0.001$ \\
\hline \multicolumn{6}{|c|}{ Inflammatory Markers } \\
\hline IL-6 (pg/ml) & $2.3(1.1-4.4)$ & $2.6(1.5-5.0)$ & $1.9(0.9-4.1)$ & 0.20 & 0.23 \\
\hline TNF- a (pg/ml) & $1.1(0.5-1.6)$ & $\begin{array}{l}0.41(0.1- \\
1.5)\end{array}$ & $1.5(0.8-1.8)$ & $<.001$ & $<0.001$ \\
\hline
\end{tabular}




\begin{tabular}{|c|c|c|c|c|c|}
\hline Parameters & All & Normal & MetS & \multirow{2}{*}{$\begin{array}{l}\mathrm{P}- \\
\text { value }\end{array}$} & \multirow{3}{*}{$\begin{array}{l}\text { Age adjusted } \mathrm{P}- \\
\text { value }\end{array}$} \\
\hline N & 200 & $100(50 / 50)$ & $100(44 / 56)$ & & \\
\hline Age (years) & $38.7 \pm 8.3$ & $35.4 \pm 7.9$ & $41.9 \pm 7.2$ & $\begin{array}{l}<.001 \\
0.001\end{array}$ & \\
\hline CRP (ng/ml) & $\begin{array}{l}3241(1012- \\
5986)\end{array}$ & $\begin{array}{l}2010(578- \\
4441)\end{array}$ & $\begin{array}{l}4388(1724- \\
6185)\end{array}$ & $<.001$ & $<0.001$ \\
\hline \multicolumn{6}{|l|}{ Protein } \\
\hline ZAG (ug/ml) & $46.0 \pm 17.3$ & $43.8 \pm 19.5$ & $48.1 \pm 14.8$ & 0.08 & 0.04 \\
\hline
\end{tabular}

\section{Correlation of ZAG level with proinflammatory cytokines in different metabolic component}

We observed a positive correlation between ZAG and CRP in non-central obesity group $(R=0.31, p<0.01)$, as well in female group $(R=0.42, p<0.01)$. Also, CRP and ZAG have positive association with hypertensive group $(R=0.28, p<0.05)$, and in hypertensive female group $(R=0.40, p<0.01)$. While TNF-a and ZAG have a negative association in the non-hypertensive males $(R=-0.47, p<0.05)$. Also, there was negative association between IL- 6 and ZAG level in hyperglycemic group in all subjects $(R=-0.26, p<$ 0.05). In female group with normal HDL-cholesterol and triglycerides level, there were significant positive association between CRP and ZAG $(R=0.44, p<0.01),(R=0.35, p<0.05)$ respectively (Table 2$)$. To understand the association between serum ZAG levels and MetS components, subjects in the MetS and its components divided into three parts according to serum ZAG tertiles (Q1: <40.3; Q2: 40.4- 51.7; Q3: $>51.7)$ as displayed in Table 3 Logistic Regression analysis showed that MetS and hypertriglyceridemia at risk for ZAG. 
Table 2

Correlation analysis between ZAG ( $\mathrm{ug} / \mathrm{ml}$ ) with Proinflammatory Cytokines in association with different metabolic components

\begin{tabular}{|c|c|c|c|c|c|c|}
\hline \multirow[t]{2}{*}{ Parameters } & \multicolumn{2}{|l|}{ All } & \multicolumn{2}{|l|}{ Males } & \multicolumn{2}{|c|}{ Females } \\
\hline & No & Yes & No & Yes & No & Yes \\
\hline \multicolumn{7}{|c|}{ Central Obesity: Waist circumference $>101.6 \mathrm{~cm}$ (males), $>88.9 \mathrm{~cm}$ (females) } \\
\hline IL-6 (pg/ml) & -0.10 & -0.13 & -0.14 & -0.20 & -0.06 & -0.07 \\
\hline TNF- a $(\mathrm{pg} / \mathrm{ml})$ & 0.00 & -0.06 & 0.07 & -0.23 & 0.00 & 0.05 \\
\hline $\operatorname{CRP}(\mu \mathrm{g} / \mathrm{ml})$ & $0.31^{\star *}$ & -0.01 & 0.21 & -0.12 & $0.42^{\star \star}$ & 0.07 \\
\hline \multicolumn{7}{|c|}{ Hypertension: Systolic BP > $130 \mathrm{mmHg}$ and/or diastolic BP > $85 \mathrm{mmHg}$} \\
\hline IL-6 (pg/ml) & -0.08 & -0.16 & -0.08 & -0.23 & -0.09 & -0.08 \\
\hline TNF- $\mathrm{a}(\mathrm{pg} / \mathrm{ml})$ & -0.09 & -0.02 & $-0.47^{*}$ & 0.12 & 0.09 & -0.01 \\
\hline $\mathrm{CRP}(\mu \mathrm{g} / \mathrm{ml})$ & 0.11 & $0.28^{*}$ & 0.08 & 0.04 & 0.15 & $0.40^{\star \star}$ \\
\hline \multicolumn{7}{|c|}{ Hyperglycemia: >5.6 mmol// } \\
\hline IL-6 (pg/ml) & 0.03 & $-0.26^{*}$ & -0.06 & -0.27 & 0.09 & -0.25 \\
\hline TNF- $a(p g / m l)$ & -0.20 & 0.13 & -0.08 & -0.08 & -0.14 & 0.22 \\
\hline $\mathrm{CRP}(\mu \mathrm{g} / \mathrm{ml})$ & 0.09 & $0.27^{*}$ & -0.06 & 0.29 & 0.25 & 0.28 \\
\hline \multicolumn{7}{|c|}{ Hypertriglyceridemia: $\geq 1.7 \mathrm{mmol} / \mathrm{I}$} \\
\hline IL-6 (pg/ml) & -0.13 & -0.05 & -0.19 & -0.05 & -0.09 & -0.05 \\
\hline TNF- $a(p g / m l)$ & 0.05 & -0.21 & -0.48 & -0.10 & 0.20 & -0.22 \\
\hline $\mathrm{CRP}(\mu \mathrm{g} / \mathrm{ml})$ & 0.15 & 0.12 & -0.13 & 0.14 & $0.35^{\star}$ & 0.10 \\
\hline \multicolumn{7}{|c|}{ Low HDL-Cholesterol: <1.03 mmol/l (males), $<1.3 \mathrm{mmol} / \mathrm{l}$ (females) } \\
\hline IL-6 (pg/ml) & -0.08 & -0.13 & 0.08 & -0.33 & -0.21 & 0.08 \\
\hline TNF- $\mathrm{a}(\mathrm{pg} / \mathrm{ml})$ & -0.11 & -0.02 & -0.55 & 0.16 & 0.18 & -0.09 \\
\hline $\mathrm{CRP}(\mu \mathrm{g} / \mathrm{ml})$ & 0.22 & 0.10 & 0.02 & 0.12 & $0.44^{\star \star}$ & 0.10 \\
\hline
\end{tabular}


Table 3

Logistic Regression analysis for ZAG tertile on MetS and its components

\section{Quartile}

Crude

Multivariate Model

OR $(95 \% \mathrm{Cl})$

P-Value

OR $(95 \% \mathrm{Cl})$

P-Value

\section{Central Obesity}

$1(<40.3)$

1

0.22

1

0.13

2 (40.4-51.7)

$1.6(0.8-3.1)$

0.13

$1.8(0.8-3.6)$

0.10

$3(>51.7)$

$1.7(0.9-3.5)$

$1.9(0.9-3.9)$

Hypertension

$\begin{array}{lllll}1(<40.3) & 1 & 0.22 & 1 & 0.27 \\ 2(40.4-51.7) & 0.6(0.3-1.3) & 0.17 & 0.7(0.3-1.4) & 0.16 \\ 3(>51.7) & 0.6(0.3-1.2) & & 0.6(0.3-1.3) & \end{array}$

\section{Hyperglycemia}

$\begin{array}{lllll}1(<40.3) & 1 & 0.98 & 1 & 0.79 \\ 2(40.4-51.7) & 1.0(0.5-2.0) & 0.94 & 1.1(0.5-2.3) & 0.89 \\ 3(>51.7) & 1.0(0.5-2.1) & & 1.0(0.5-2.2) & \end{array}$

\section{Hypertriglyceridemia}

$\begin{array}{lllll}1(<40.3) & 1 & 0.005 & 1 & 0.001 \\ 2(40.4-51.7) & 2.8(1.4-5.7) & 0.02 & 3.7(1.6-8.3) & 0.009 \\ 3(>51.7) & 2.4(1.2-4.9) & & 2.9(1.3-6.4) & \end{array}$

\section{Low HDL-Cholesterol}

$\begin{array}{lllll}1(<40.3) & 1 & 0.11 & 1 & 0.11 \\ 2(40.4-51.7) & 1.8(0.8-3.6) & 0.31 & 1.8(0.8-3.7) & 0.31 \\ 3(>51.7) & 1.4(0.7-2.9) & & 1.4(0.7-2.9) & \end{array}$

\section{Metabolic Syndrome}

$\begin{array}{lllll}1(<40.3) & 1 & 0.02 & 1 & 0.006 \\ 2(40.4-51.7) & 2.3(1.1-4.6) & 0.062 & 3.0(1.3-6.6) & 0.04 \\ 3(>51.7) & 1.9(0.9-4.0) & & 2.3(1.1-5.1) & \end{array}$

Note: Data presented Odd Ratio $(95 \% \mathrm{Cl})$. P-Value $<0.05,0.01$ level will be significant. Multivariate logistic regression analysis was adjusted. 
Lastly, AUC was done to determine the possibility of ZAG to be used as a clinical biomarker for the diagnosis of MetS and/or its components (Table 4). In all subjects, ZAG was not a significant biomarker for MetS [AUC 0.57 (95\% Cl 0.5-0.6; $p=0.10$ ] and a significant but poor biomarker of hypertriglyeridemia [0.61 $(0.5-0.7 ; p=0.01]$. When stratified according to sex, ZAG is a fair biomarker for hypertriglyceridemia in males [0.7 (95\% Cl 0.6-0.8; $p=0.003$ ] and a poor but significant biomarker for low-HDL cholesterol in females [0.6 (95\% Cl 0.5-0.8; $p=0.02]$ (Fig. 1).

Table 4

Area Under the Curve for Metabolic Syndrome and its components against ZAG

\begin{tabular}{|c|c|c|c|c|c|c|}
\hline \multirow{2}{*}{$\begin{array}{l}\text { MetS \& } \\
\text { Components }\end{array}$} & \multicolumn{2}{|l|}{ All } & \multicolumn{2}{|l|}{ Males } & \multicolumn{2}{|l|}{ Females } \\
\hline & AUC & $\begin{array}{l}\text { P- } \\
\text { value }\end{array}$ & AUC & $\begin{array}{l}\mathrm{P}- \\
\text { value }\end{array}$ & AUC & $\begin{array}{l}\text { P- } \\
\text { value }\end{array}$ \\
\hline MetS & $\begin{array}{l}0.57(0.49- \\
0.65)\end{array}$ & 0.10 & $\begin{array}{l}0.54(0.42- \\
0.67)\end{array}$ & 0.515 & $\begin{array}{l}0.59(0.48- \\
0.70)\end{array}$ & 0.11 \\
\hline Obesity & $\begin{array}{l}0.55(0.47- \\
0.64)\end{array}$ & 0.21 & $\begin{array}{l}0.54(0.42- \\
0.66)\end{array}$ & 0.568 & $\begin{array}{l}0.58(0.46- \\
0.68)\end{array}$ & 0.24 \\
\hline Hypertension & $\begin{array}{l}0.47(0.38- \\
0.55)\end{array}$ & 0.43 & $\begin{array}{l}0.50(0.37- \\
0.63)\end{array}$ & 0.971 & $\begin{array}{l}0.45(0.33- \\
0.56)\end{array}$ & 0.35 \\
\hline High Glucose & $\begin{array}{l}0.50(0.42- \\
0.58)\end{array}$ & 0.95 & $\begin{array}{l}0.45(0.33- \\
0.58)\end{array}$ & 0.464 & $\begin{array}{l}0.54(0.42- \\
0.65)\end{array}$ & 0.54 \\
\hline High Triglycerides & $\begin{array}{l}0.61(0.52- \\
0.69)\end{array}$ & 0.01 & $\begin{array}{l}0.69(0.57- \\
0.81)\end{array}$ & 0.003 & $\begin{array}{l}0.53(0.42- \\
0.64)\end{array}$ & 0.62 \\
\hline Low HDL & $\begin{array}{l}0.56(0.47- \\
0.65)\end{array}$ & 0.12 & $\begin{array}{l}0.47(0.34- \\
0.60)\end{array}$ & 0.63 & $\begin{array}{l}0.64(0.53- \\
0.75)\end{array}$ & 0.018 \\
\hline \multicolumn{7}{|c|}{$\begin{array}{l}\text { Note: Data presented as Area Under the Curve (AUC) and } 95 \% \mathrm{Cl} \text {. P-value }<0.05 \text { considered } \\
\text { significant. }\end{array}$} \\
\hline
\end{tabular}

\section{Discussion}

In this study we investigated the relationship between circulating zinc a 2-glycoprotein (ZAG), concentrations and MetS components and analyze the effects of the circulating levels of ZAG on Proinflammatory Cytokines, CRP and TNF-a in Saudi patient with MetS compare to normal participants without MetS. To the best of our knowledge, there are a few studies on ZAG level in MetS patient worldwide, and this study is the first to be conducted in Saudi Arabia. The current study showed that circulating ZAG levels in MetS patients were significantly higher than in those without MetS in age dependent manner. In contrast, the results of a study by Lei et al. ${ }^{13}$ and Wang et al. ${ }^{14}$ revealed that circulating ZAG levels were lower in MetS subjects than in those without MetS. This controversy between 
the findings could be due to differences in the study design, including sample size, age, and more importantly subjects involved in the two studies were from different population. Age effect on ZAG levels was confirmed in a recent study by Tan et al. ${ }^{15}$ were they reported significantly lower circulating ZAG level in young women with MetS components. Whereas, in agreement with findings of our study, the results of Yeung et al. ${ }^{7}$ study on Chinese subjects have shown that ZAG levels were significantly elevated in MetS subjects and it was also elevated progressively with an increasing number of components of the MetS. Our results revealed that ZAG also correlate positively with some of MetS component and significantly with triglycerides, Waists, and inversely correlate with HDL-cholesterol. Similar findings were shown by previous study ${ }^{7}$. Animal studies have shown that ZAG act as a regulator of lipid metabolism, and our results multiplied these finding and we showed significantly positive correlation between ZAG and triglyceride, and inverse correlation with HDL-cholesterol ${ }^{16,17}$. These clinical finding suggest that ZAG may play an important regulatory role in lipid metabolism in humans as well. As ZAG have been shown to possess beneficial effect on mice obesity reduction, decreasing body fat content, and stimulating lipolysis in differentiated adipocytes in vitro ${ }^{16}$. Based on research finding we speculate that, the observed elevation of serum level of ZAG in MetS patient could be a compensatory process for the human body to overcome the metabolic stress induced by obesity. Or alternatively, obesity, could be contributing to ZAG resistance which leads to its upregulation. SBP, DBP and Glucose level were significantly higher in MetS patient than the healthy control, but there was no significant correlation between ZAG and hypertension or fasting glucose. However, in previous studies, it was found that there is a negative correlation between ZAG and hypertension ${ }^{13}$. Elevation of visceral adipocytes in MetS disturbs the adipocytokine secretion and leads to a low-grade chronic inflammatory state by the macrophages of adipocytes. This inflammatory state is found to be associated with IR and MetS ${ }^{18}$. CRP is well known marker for obesity-related inflammation and the Mets, thus we measured its levels. Subjects with MetS had markedly higher CRP level compared to patients without MetS, this finding came in agreement with other study ${ }^{19}$. CRP level also was significantly higher in obese patient than normal subjects. Furthermore, both CRP and ZAG have been found significantly and positively associated with each other ${ }^{7}$. Apparently, inflammatory cytokines are able to induce IR in both adipose tissue and muscle.in case of obesity, adipocytes produce plenty of cytokines such as tumor necrosis factor-a and interleukin-6, IL-6 the primary stimulator of the production of CRP in the liver. These responses seems to link MetS and inflammation, and explain the increase of CRP level in MetS patients, and the strong relationship between $\mathrm{BMI}$ and CRP levels ${ }^{7,20}$.

Proinflammatory TNF- a plays a crucial role in the inflammatory cytokine cascade that is involved in multiple disease pathogenesis. TNF-a has been studied by Gormez et al. ${ }^{18}$ and it was found significantly higher in MetS patient than normal subjects. The significant increase in TNF-a level was due to the increased its gene expression in Mets patient compare to control ${ }^{18}$. In addition, TNF-a level was found higher in obese patient than in non-obese in study ${ }^{21}$. We found that TNF- a was higher in female than male. Interestingly, our data reveal a positive association between TNF-a and ZAG in normal subjects but negative association in MetS subjects. This negative association was reported in cultured human

Page $11 / 16$ 
adipocytes upon treated with TNF- $a$, which lowered ZAG mRNA levels. Among inflammatory markers, TNF-a is one of the most important inflammatory cytokines that is critically involved in the development of insulin resistance and pathogenesis of T2DM. Additionally, neutralization of TNF-a also improved the hepatic IR in animal model, also TNF- a -deficient mice have shown improve in sensitivity to insulin ${ }^{22,23}$. With regards to the Proinflammatory cytokine IL- 6 level, there was no significant change of IL- 6 level found between normal and MetS subjects, but there was significant decrease in male subjects with MetS when compare to normal male subjects. Also, there were negative correlation between IL- 6 and ZAG in normal and MetS subjects. We have no knowledge of any previous of study that has studied the relationship between ZAG and interleukins 6 . IL- 6 was found to be elevated in obesity and type 2 diabetes mellites patients, while Circulating ZAG levels in the serum and adipose tissue of obese patients and obese mice are notably lower in compare to normal subjects and ZAG were found to be oppositely associated with insulin resistance in type 2 diabetes mellites patients ${ }^{24-26}$.

\section{Conclusions}

This study shows a significance increase in circulating ZAG levels in patients with MetS comparing to healthy control. ZAG was positively associated with some of MetS component like triglycerides, Waists as well with inflammatory CRP, while inversely correlate with HDL-cholesterol. These findings support the pathological role of ZAG in human obesity and its related metabolic disorders. To demonstrate serum ZAG diagnostic efficacy as a MetS marker, it will require further studies involving bigger size pupation to validate the use of ZAG as a biomarker for Mets and provide a more definitive link between ZAG and Met

\section{Declarations}

\section{Author Contributions:}

Conceptualization, N.M.A.;; methodology, S.S., A.M.A.; formal analysis, L.F.A., A.M.A., O.E.A., data curation and statistical analysis, M.N.K.K., S.D.H.; writing-original draft preparation, L.F.A.; writing-review and editing, S.S., A.M.A., N.M.A.; supervision, N.M.A., A.M.A.; funding acquisition, N.M.A. All authors have read and agreed to the published version of the manuscript.

\section{Funding:}

This research was funded by the Deanship of Scientific Research in King Saud University, Riyadh, Saudi Arabia.

\section{Institutional Review Board Statement:}

Ethical approval was obtained from the Ethics Committee of the College of Science Research Center, King Saud University, Riyadh, Saudi Arabia (approval No. E-20-5369). All methods were carried out in 


\section{Informed Consent Statement:}

Written informed consent was obtained from all subjects involved in the study.

\section{Data Availability Statement:}

All data are available within the article.

\section{Acknowledgments:}

The authors would also like to thank the research team from different primary care centers for the recruitment of subjects.

\section{Conflicts of Interest:}

The authors declare no conflict of interest.

\section{References}

1. McCracken, E., Monaghan, M. \& Sreenivasan, S. Pathophysiology of the metabolic syndrome. Clin Dermatol, 36, 14-20 https://doi.org/10.1016/j.clindermatol.2017.09.004 (2018).

2. Al-Nozha, M. et al. Metabolic syndrome in Saudi Arabia. Saudi Med J, 26, 1918-1925 (2005).

3. Eckel, R. H., Grundy, S. M. \& Zimmet, P. Z. The metabolic syndrome., 365, 1415-1428 https://doi.org/10.1016/S0140-6736(05)66378-7 (2005).

4. Gohda, T. et al. Identification of epistatic interaction involved in obesity using the KK/Ta mouse as a Type 2 diabetes model: is Zn-alpha2 glycoprotein-1 a candidate gene for obesity?, 52, 2175-2181 https://doi.org/10.2337/diabetes.52.8.2175 (2003).

5. Tedeschi, S. et al. Serum adipokine zinc alpha2-glycoprotein and lipolysis in cachectic and noncachectic heart failure patients: relationship with neurohormonal and inflammatory biomarkers. Metabolism, 61, 37-42 https://doi.org/10.1016/j.metabol.2011.05.011 (2012).

6. Hassan, M. I., Waheed, A., Yadav, S., Singh, T. P. \& Ahmad, F. Zinc alpha 2-glycoprotein: a multidisciplinary protein. Mol Cancer Res, 6, 892-906 https://doi.org/10.1158/1541-7786.MCR-072195 (2008).

7. Yeung, D. C., Lam, K. S., Wang, Y., Tso, A. W. \& Xu, A. Serum zinc-alpha2-glycoprotein correlates with adiposity, triglycerides, and the key components of the metabolic syndrome in Chinese subjects. $J$ Clin Endocrinol Metab, 94, 2531-2536 https://doi.org/10.1210/jc.2009-0058 (2009). 
8. Xiao, X. et al. Zinc alpha2 glycoprotein alleviates palmitic acid-induced intracellular lipid accumulation in hepatocytes. Mol Cell Endocrinol, 439, 155-164 https://doi.org/10.1016/j.mce.2016.06.003 (2017).

9. Elattar, S., Dimri, M. \& Satyanarayana, A. The tumor secretory factor ZAG promotes white adipose tissue browning and energy wasting. FASEB J, 32, 4727-4743 https://doi.org/10.1096/fj.201701465RR (2018).

10. Al-Daghri, N. M., Al-Attas, O. S., Wani, K., Sabico, S. \& Alokail, M. S. Serum Uric Acid to Creatinine Ratio and Risk of Metabolic Syndrome in Saudi Type 2 Diabetic Patients. Sci Rep, 7, 12104 https://doi.org/10.1038/s41598-017-12085-0 (2017).

11. Grundy, S. M. Obesity, metabolic syndrome, and cardiovascular disease. J Clin Endocrinol Metab, 89, 2595-2600 https://doi.org/10.1210/jc.2004-0372 (2004).

12. Lv, J. et al. Effects of intensive blood pressure lowering on cardiovascular and renal outcomes: a systematic review and meta-analysis. PLoS Med, 9, e1001293 https://doi.org/10.1371/journal.pmed.1001293 (2012).

13. Lei, L. et al. Circulating zinc-alpha2-glycoprotein levels are low in newly diagnosed patients with metabolic syndrome and correlate with adiponectin. Nutr Metab (Lond), 14, 53 https://doi.org/10.1186/s12986-017-0210-6 (2017).

14. Wang, L. et al. Low Serum ZAG Levels Correlate With Determinants of the Metabolic Syndrome in Chinese Subjects. Front Endocrinol (Lausanne), 11, 154 https://doi.org/10.3389/fendo.2020.00154 (2020).

15. Tan, X. et al. Association of metabolic syndrome components with circulating levels of cytokine clusters in young women. Endocr Connect, 10, 66-75 https://doi.org/10.1530/EC-20-0569 (2021).

16. Russell, S. T. \& Tisdale, M. J. Studies on the anti-obesity activity of zinc-alpha2-glycoprotein in the rat. Int J Obes (Lond), 35, 658-665 https://doi.org/10.1038/ijo.2010.193 (2011).

17. Russell, S. T., Zimmerman, T. P., Domin, B. A. \& Tisdale, M. J. Induction of lipolysis in vitro and loss of body fat in vivo by zinc-alpha2-glycoprotein. Biochim Biophys Acta, 1636, 59-68 https://doi.org/10.1016/j.bbalip.2003.12.004 (2004).

18. Gormez, S. et al. Adipose tissue gene expression of adiponectin, tumor necrosis factor-alpha and leptin in metabolic syndrome patients with coronary artery disease. Intern Med, 50, 805-810 https://doi.org/10.2169/internalmedicine.50.4753 (2011).

19. Stejskal, D. et al. Determination of serum zinc-alpha-2-glycoprotein in patients with metabolic syndrome by a new ELISA. Clin Biochem, 41, 313-316 https://doi.org/10.1016/j.clinbiochem.2007.11.010 (2008).

20. Grundy, S. M. et al. Diagnosis and management of the metabolic syndrome: an American Heart Association/National Heart, Lung, and Blood Institute Scientific Statement., 112, 2735-2752 https://doi.org/10.1161/CIRCULATIONAHA.105.169404 (2005).

21. Park, H. S., Park, J. Y. \& Yu, R. Relationship of obesity and visceral adiposity with serum concentrations of CRP, TNF-alpha and IL-6. Diabetes Res Clin Pract, 69, 29-35 
https://doi.org/10.1016/j.diabres.2004.11.007 (2005).

22. Popa, C., Netea, M. G., van Riel, P. L., van der Meer, J. W. \& Stalenhoef, A. F. The role of TNF-alpha in chronic inflammatory conditions, intermediary metabolism, and cardiovascular risk. J Lipid Res, 48, 751-762 https://doi.org/10.1194/jlr.R600021-JLR200 (2007).

23. Akash, M. S. H., Rehman, K. \& Liaqat, A. Tumor Necrosis Factor-Alpha: Role in Development of Insulin Resistance and Pathogenesis of Type 2 Diabetes Mellitus. J Cell Biochem, 119, 105-110 https://doi.org/10.1002/jcb.26174 (2018).

24. Gong, F. Y. et al. Zinc-alpha2-glycoprotein is involved in regulation of body weight through inhibition of lipogenic enzymes in adipose tissue. Int J Obes (Lond), 33, 1023-1030 https://doi.org/10.1038/ijo.2009.141 (2009).

25. Esser, N., Legrand-Poels, S., Piette, J., Scheen, A. J. \& Paquot, N. Inflammation as a link between obesity, metabolic syndrome and type 2 diabetes. Diabetes Res Clin Pract, 105, 141-150 https://doi.org/10.1016/j.diabres.2014.04.006 (2014).

26. Barraco, G. M., Luciano, R. \& Manco, M. Zinc-alpha2 -glycoprotein is associated with insulin resistance in children. Obesity (Silver Spring), 23, 5-6 https://doi.org/10.1002/oby.20948 (2015).

\section{Figures}

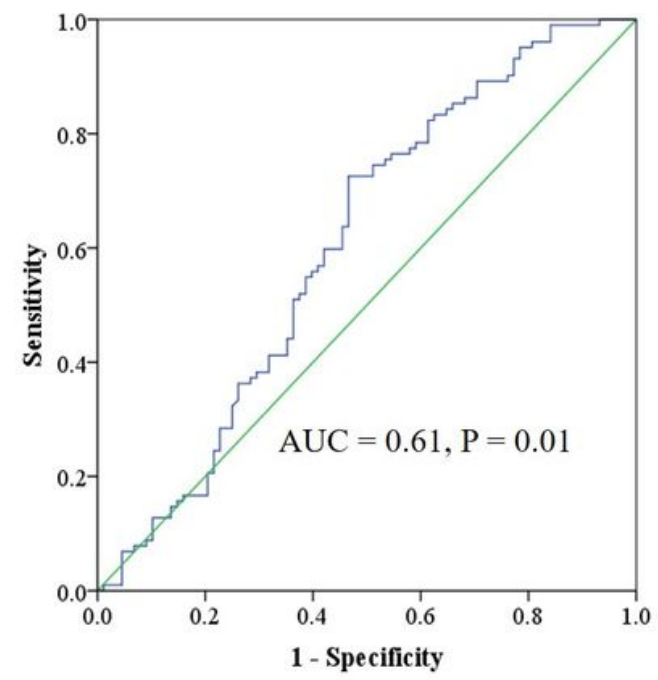

A. Hypertriglyceridemia (All)

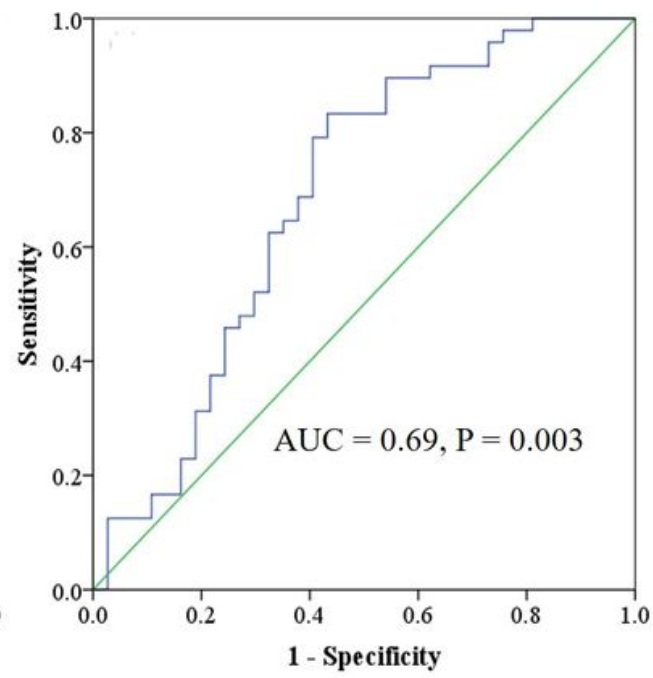

B. Hypertriglyceridemia (Males)

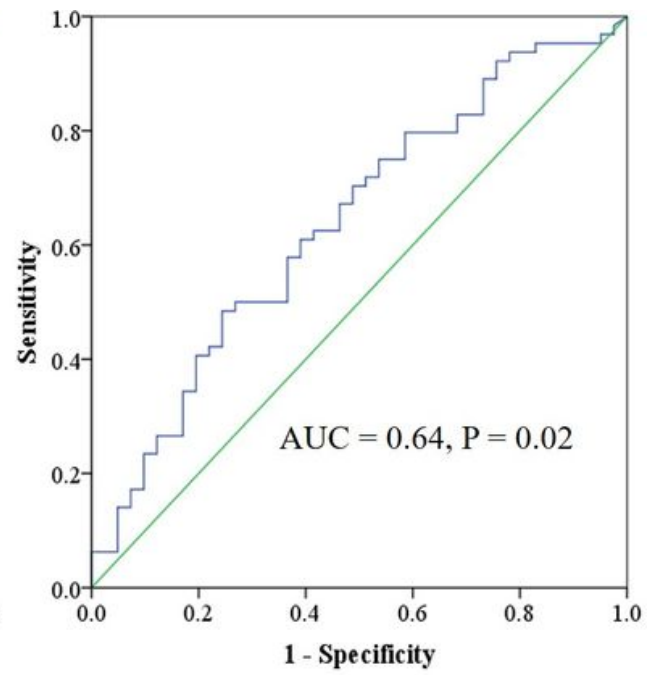

C. Low HDL (Females)

\section{Figure 1}

AUC was done to determine the possibility of ZAG to be used as a clinical biomarker for the diagnosis of MetS and/or its components (Table 4). In all subjects, ZAG was not a significant biomarker for MetS [AUC 0.57 (95\% Cl 0.5-0.6; $p=0.10]$ and a significant but poor biomarker of hypertriglyeridemia [0.61 (0.5-0.7; $p=0.01]$. When stratified according to sex, ZAG is a fair biomarker for hypertriglyceridemia in males [0.7 
(95\% $\mathrm{Cl} 0.6-0.8 ; \mathrm{p}=0.003]$ and a poor but significant biomarker for low-HDL cholesterol in females [0.6 $(95 \% \mathrm{Cl} 0.5-0.8 ; \mathrm{p}=0.02$ ] (figure 1$)$.

\section{Supplementary Files}

This is a list of supplementary files associated with this preprint. Click to download.

- SupplementaryTableS1.docx 